\title{
Seroprevalence and Associated Risk Factors of Brucellosis among Indigenous Cattle in the Adamawa and North Regions of Cameroon
}

\author{
J. Awah-Ndukum $\mathbb{D}^{1},{ }^{1}$ M. M. M. Mouiche, ${ }^{1}$ H. N. Bayang, ${ }^{2}$ V. Ngu Ngwa $\left(\mathbb{D},{ }^{1}\right.$ \\ E. Assana, ${ }^{1}$ K. J. M. Feussom, ${ }^{3}$ T. K. Manchang, ${ }^{2}$ and P. A. Zoli ${ }^{1}$ \\ ${ }^{1}$ School of Veterinary Medicine and Sciences, University of Ngaoundéré, Ngaoundéré, Cameroon \\ ${ }^{2}$ Institute of Agricultural Research for Development, Veterinary Research Laboratory, Wakwa Regional Center, Ngaoundéré, Cameroon \\ ${ }^{3}$ Epidemio-Surveillance Service, Ministry of Livestock, Fisheries, Animal Industries, Yaoundé, Cameroon
}

Correspondence should be addressed to J. Awah-Ndukum; awahndukum@yahoo.co.uk

Received 23 May 2017; Revised 15 November 2017; Accepted 3 December 2017; Published 8 January 2018

Academic Editor: Douglas Morck

Copyright (C) 2018 J. Awah-Ndukum et al. This is an open access article distributed under the Creative Commons Attribution License, which permits unrestricted use, distribution, and reproduction in any medium, provided the original work is properly cited.

\begin{abstract}
A cross-sectional seroprevalence study was conducted on cattle in the North and Adamawa Regions of Cameroon to investigate the status of bovine brucellosis and identify potential risk factors. The diagnosis was carried out using the Rose Bengal Plate test (RBPT) and indirect ELISA (i-ELISA), while questionnaires were used to evaluate risk factors for bovine brucellosis in cattle. The Bayesian approach was used to evaluate the diagnostic tests' sensitivity and specificity. The overall individual level $(n=1031)$ and herd level $(n=82)$ seroprevalence were $5.4 \%(0.4-10.5)$ and $25.6 \%(16.2-35.0)$, respectively. Bayesian analysis revealed sensitivity of $58.3 \%$ (26.4-92.7) and 89.6\% (80.4-99.4) and specificity of 92.1\% (88.7-95.2) and 95.7\% (91.1-99.7) for RBPT and i-ELISA, respectively. Management related factors such as region, locality, herd size, and knowledge of brucellosis and animal related factors such as sex and age were significantly associated with seropositivity of brucellosis. Zoonotic brucellosis is a neglected disease in Cameroon. The study highlights the need for control measures and the need to raise public awareness of the zoonotic occurrence and transmission of bovine brucellosis in the country. An integrated disease control strategy mimicking the one health approach involving medical personnel, veterinarians, related stakeholders, and affected communities cannot be overemphasized.
\end{abstract}

\section{Introduction}

Brucellosis is an economically important and widespread zoonosis in the world caused by bacteria of the genus Brucella, which tend to infect specific animal species [1]. Brucellosis in cattle is usually caused by B. abortus, in sheep and goats by $B$. melitensis, and in swine by $B$. suis [2]. However, bovine brucellosis has occasionally been caused by Brucella melitensis and Brucella suis in some instances where mixed farming is practiced $[2,3]$, characterized by late term abortion, infertility, and reduced milk production $[1,2,4]$. Human brucellosis is mainly associated with $B$. abortus, $B$. melitensis, and B. suis [2]. Bovine brucellosis is widespread in Africa, where it remains one of the most important zoonotic diseases $[5,6]$, with prevalence ranging from $5 \%$ to over $70 \%$ in sub-Sahara African countries $[1,7,8]$ including Cameroon [9-11]. Brucellosis has important public health significance but it is a "neglected zoonosis" in Cameroon. Poor implementation of essential control measures of zoonoses including animal brucellosis (e.g., restricting movement of infected cattle, reporting disease to the veterinary services, testing of animals) has been reported in the country [12]. There is little concerted veterinary and medical efforts to maximize zoonoses detection rates, while active involvement of the populations at risk and good health systems are also lacking.

The surveillance of bovine brucellosis in most countries in Africa including Cameroon is generally poor [6]. Lack of public awareness and poor or low income communities 
have been largely associated with the neglect of the disease [13]. The persistence and wide prevalence ranges of bovine brucellosis in sub-Sahara Africa are influenced by several factors associated with disease transmission between herds, factors influencing the maintenance and spread of infection within herds, purchase of infected cattle from livestock market for replacement or upgrading, nature of the animal production system, demographic factors, regulatory issues, climate, deforestation, and wildlife interaction $[3,7,14,15]$. Although poorly implemented, the control of major zoonoses in Cameroon is mainly through the regulation of animal movement and postmortem examination of carcasses [12] such that appropriate preventive measures and planning of effective control programs cannot be achieved. Furthermore, vaccination of cattle against brucellosis is not practiced in Cameroon.

Serological diagnosis of brucellosis consists of testing sera by several tests, usually a screening test of high sensitivity, followed by a confirmatory test of high specificity [16]. However, presumptive seroprevalence studies in parts of Cameroon have shown that bovine brucellosis is endemic. For instance, using Rose Bengal Plate test (RBPT), complement fixation, indirect Enzyme-Linked Immunosorbent Assay (i-ELISA), and slow agglutination of Wright with ethylenediaminetetraacetic acid (EDTA) tests, seroprevalence rates in the range of $3-16 \%$ of brucellosis in cattle in parts of the Western Highlands and Adamawa Regions of Cameroon [9-11, 15, $17,18]$ have been recorded. However, the performance and accuracy of a diagnostic test can be evaluated by comparing its sensitivity and specificity with those of a goal test or analyzing it with several tests using latent models [19-23]. The practice of transhumance (seasonal movement of people with their livestock from one pasture ground to another to improve grazing) among pastoralists, uncontrolled crossboundary movements of animals, and mixing of herds during veterinary interventions are common and can facilitate the spread of the disease in Cameroon. The burden of brucellosis among various cattle populations and risk factors associated with the disease in different geographical parts of the country are not known.

Therefore, this study was carried out to evaluate diagnostic performance and accuracy of Rose Bengal Plate test (RBPT) and indirect Enzyme-Linked Immunosorbent Assay (i-ELISA) tests for screening and confirmation of bovine brucellosis using Bayesian method. The study also estimates the true seroprevalence of bovine brucellosis and assesses the potential risk factors for evidence-based disease control of the disease in Cameroon.

\section{Materials and Methods}

2.1. Description of Study Areas. The study was carried out in the two adjacent regions, the Adamawa and North Regions (Figure 1), of Cameroon $\left(8^{\circ}-13^{\circ} \mathrm{N}\right.$ and $\left.11^{\circ}-16^{\circ} \mathrm{E}\right)$. The Adamawa Region is located in the Savannah Guinean Highland and the North Region in the Sudano-Sahelian, in the mid to high altitude zones of the country. Average annual precipitations of $1200-1600 \mathrm{~mm}$, rainy season from about mid-March to October, temperature of $14^{\circ}-26^{\circ} \mathrm{C}$ for the
Adamawa Region and annual precipitations of 400-900 mm, four months of rainy season (July to October), temperature of $21^{\circ}-36^{\circ} \mathrm{C}$ for the North Region have been noted. The Adamawa and North Regions are among the principal cattle production zones in Cameroon [24], and both regions were retained for the Dairy Development Program (Program to Improve Agricultural Productivity/Support for Development of the Dairy Sector (PAPA/ADFL)) of indigenous breeds (Guadali in Adamawa Region and Fulani/Bororo in North Region) to improve the availability of milk. The communities of the study areas are pure pastoralists (30\%) and agropastoralists $(65 \%)$ and practice predominantly the traditional systems of husbandry. The socioeconomic, political, cultural, and religious activities of the farmers are heavily dependent on cattle. Bos indicus, Bos Taurus (Namchi), and exotic (Montbeliarde, Holstein, Charolaise) breeds of cattle as well as their crossbreeds are reared in the study areas.

2.2. Selection of Study Animals. A cross-sectional study was carried out during the period of January to June 2014 using a stratified sampling procedure to select herds and then individual cattle per herd. A herd prevalence rate of 16\% [18] was used to estimate the sample sizes of herds as previously described [25]. Briefly, the selection of cattle herds was done by the random-number generation method of cattle keeping communities, cattle owners, and locations of herds listed on the PAPA/ADFL program in the Adamawa and North Regions. The herd sizes ranged from 20 to 80 animals and the selection procedure took into consideration costs, season, road accessibility (including distance and time to trek to herds), and local cultural beliefs (such as being suspicious of unfamiliar events in their farms and around their animals, as well as associating visitors to animal farms with reproductive failures and poor yield and performance) because a farmer's willingness to participate was never guaranteed. Only herds with a minimum of 10 head of cattle that are $\geq 2$ years old and had spent $\geq 1$ year in the area were included in the study. Herds that cograzed were grouped together and considered as one. Eligible herds from each study region were numbered and the study herds chosen randomly without replacing the number. Selection of individual cattle to be sampled from each chosen herd was based on a systematic random sampling technique as described by Asgedom et al. [4]. Individual cattle sampling of at least ten head of cattle per herd with a $25 \%$ sampling fraction from herds with $>40$ cattle was done. However, where random sampling was not possible in a chosen herd, ten head of cattle or qualified animals (if less than ten) were selected from those present and blood samples taken. Information related to the location, husbandry practices, breed, sex, and age of the animal were noted. The ages and breeds of the animals were provided by the farmers or otherwise determined as described earlier [2628]. Herd level data including herd structure, size, history of purchases of animals, and farm management practices were also recorded.

Rose Bengal Plate test (RBPT) and indirect EnzymeLinked Immunosorbent Assay (i-ELISA) test were performed on a total of 1031 head of cattle from 82 herds (18 villages communities) owned by 52 farmers. The animals in this study 


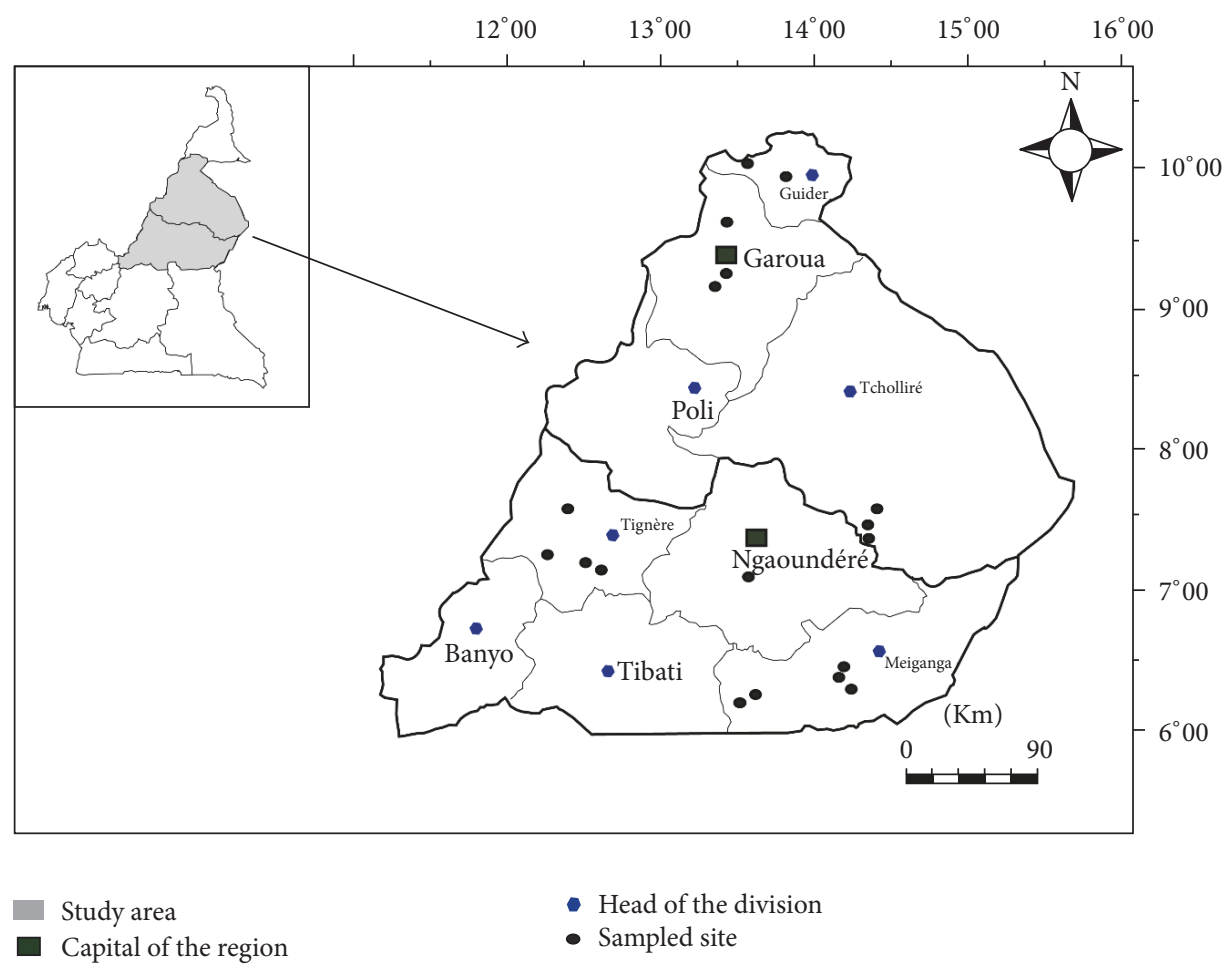

FIgure 1: Map showing study areas in the North and Adamawa Regions of Cameroon.

were reared traditionally with or without transhumance, as well as in semi-intensive and extensive systems. Apart from procedural restraining manipulations for safety purposes and jugular venipuncture for blood sampling $(\geq 5 \mathrm{ml})$ using sterile vacutainer, the animals were not subjected to suffering. Serum samples were extracted from collected blood and stored at $-20^{\circ} \mathrm{C}$ until laboratory analysis at the Veterinary Research Laboratory of IRAD, Wakwa Regional Center, Ngaoundéré, Cameroon.

2.3. Rose Bengal Plate Test. RBPT was performed as described by Alton et al. [29]. Briefly, the sera and antigen were brought to room temperature before use. Equal volumes $(30 \mu \mathrm{L})$ of standardized B. abortus antigen Weybridge strain 99 and test serum were mixed thoroughly and rotated on a glass plate using a stick applicator, and the plate was rocked for $4 \mathrm{~min}$. The appearance of agglutination, recorded as positive, within 1 minute was scored $4+(++++)$ and between 1 and 4 min was scored $1+$ to $3+(+,++$, and +++$)$ according to the different degrees of agglutination. The absence of agglutination within 4 minutes was regarded as negative (-).

\subsection{Indirect Enzyme-Linked Immunosorbent Assay. i-ELISA} (ID.Vet ${ }^{\circledR}$, Innovative Diagnostics, France) was performed according to the manufacturer's instructions and essentially as described by Limet et al. [30]. The test was conducted in 96-well polystyrene plate that was precoated with purified Brucella abortus lipopolysaccharide (LPS) antigen. A multispecies horseradish peroxidase (HRP) was used as conjugate as described by Saegerman et al. [31]. The substrate solution (TMB + DMSO $+\mathrm{H}_{2} \mathrm{O}_{2}$ ) was added after washing to eliminate excess conjugate. The coloration of antigenantibody conjugate-peroxidase complex formed depended on the quantity of anti-Brucella antibodies that was present in the specimen tested. Thus, in the presence of antibodies, a blue solution appeared which became yellow after addition of the Stop Solution, while in the absence of antibodies, no coloration appeared. The microplate was read at $450 \mathrm{~nm}$ by an automatic ELISA reader and for each sample $S / P \%$ was calculated as follows:

$$
\frac{S}{P} \%=\frac{\left(\mathrm{OD}_{\text {sample }}-\mathrm{OD}_{\mathrm{nc}}\right)}{\left(\mathrm{OD}_{\mathrm{pc}}-\mathrm{OD}_{\mathrm{nc}}\right)} \times 100,
$$

where $\mathrm{OD}_{\text {sample }}, \mathrm{OD}_{\mathrm{nc}}$, and $\mathrm{OD}_{\mathrm{pc}}$ are the readings of optical densities for the sample, negative control, and positive control, respectively. The samples were classified as positive if $S / P \% \geq 120 \%$, negative if $S / P \% \leq 110 \%$, and doubtful if $110 \%<S / P \%<120 \%$. Also, the fact that $\mathrm{OD}_{\mathrm{pc}}>0.350$ and $\mathrm{OD}_{\mathrm{pc}} / \mathrm{OD}_{\mathrm{nc}}>3$ indicated that the test was working properly.

2.5. Risk Factor Analysis. Information on risk factors for bovine brucellosis was obtained by examination of individual cattle and herds and questionnaire interview with cattle professionals/handlers whose cattle herds were used in this study. The questionnaires were structured to collect information on a range of variables including animal management and husbandry practices, demographic information, and awareness of zoonotic brucellosis.

Risk assessments of the project were performed by the researchers to avoid hazards to all persons and animals involved in the project. Ethical clearances were obtained 


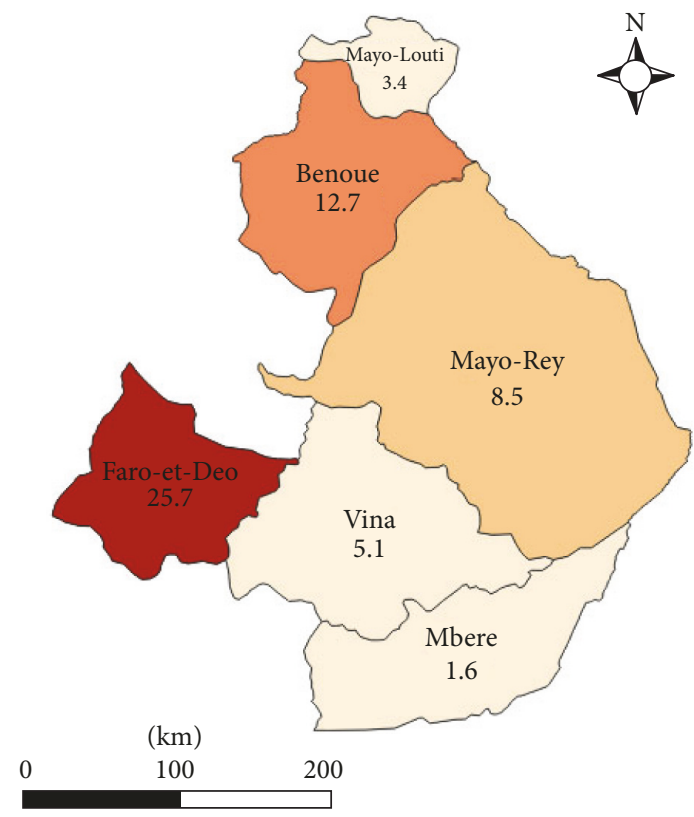

(a) Seropositivity to RBPT

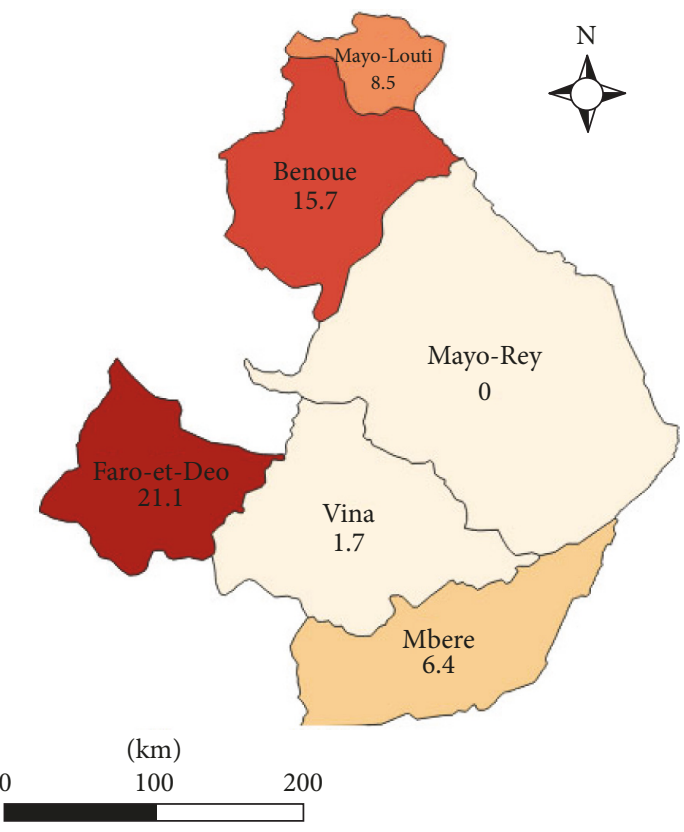

(b) Seropositivity to i-ELISA

FIGURE 2: Map showing distribution of apparent seroprevalence rates at individual animal level according to locality and diagnostic test.

from the required authorities in Cameroon (PAPA/ADFL Program Cameroon, MINEPIA delegations in Adamawa and North Regions, School of Veterinary Medicine and Sciences/University of Ngaoundéré) before carrying out the study. The purpose of the study was explained to the farmers with the assistance of local veterinarians, community leaders, and trusted intermediaries. A herd was tested and interview questionnaire survey done after informed consent was given by the owner.

2.6. Data Analysis. The Bayesian approach (the appendix in Supplementary Materials (available here)) was used to evaluate the diagnostic tests' sensitivity and specificity and estimate the true prevalence, both based on conditional dependence between the tests in the absence of a gold standard method [32]. The sensitivity and specificity of the two tests were evaluated by subjecting each sample to the two tests and the observed data of the two tests summarized in cross tabulation. Briefly, the Bayesian model for one population-two tests was modified and applied for the data using WinBUGS free software [33-35]. The true prevalence of the disease was estimated as described by Rogan and Gladen [36].

Logistic regression model was used to test the significance of the effect of different risk factors on individual and herd level seroprevalence with statistical significance set at $P<$ 0.05 .

\section{Results}

3.1. Individual and Herd Level Seroprevalence Rates of Bovine Brucellosis. Combination of tests results of 1031 head of cattle revealed an overall apparent seroprevalence of $51(5.0 \%[3.7-6.3])$ at individual animal level with 108
TABLe 1: Combined results of Rose Bengal Plate test and indirect Enzyme-Linked Immunosorbent Assay among cattle in the North and Adamawa Regions of Cameroun $(n=1031)$.

\begin{tabular}{lc}
\hline Serological results & Number of cases $(\%[95 \% \mathrm{CI}])$ \\
\hline RBPT $(+)$ & $108(10,5 \%[8,6 ; 12,4])$ \\
RBPT $(-)$ & $923(89,5 \%[87,6 ; 91,4])$ \\
i-ELISA (+) & $91(8,8 \%[7,1 ; 10,5])$ \\
i-ELISA (-) & $940(91,2 \%[89,5 ; 92,9])$ \\
RBPT (+) i-ELISA (+) & $51(5,0 \%[3,7 ; 6,3])$ \\
RBPT (+) i-ELISA (-) & $57(5,5 \%[4,1 ; 6,9])$ \\
RBPT $(-)$ i-ELISA (+) & $40(3,9 \%[2,7 ; 5,1])$ \\
RBPT $(-)$ i-ELISA (-) & $883(85,6 \%[83,4 ; 87,7])$ \\
RBPT or i-ELISA (+) & $148(14,4 \%[12,2 ; 16,5])$ \\
RBPT or i-ELISA (-) & $883(85,6 \%[83,4 ; 87,7])$ \\
\hline
\end{tabular}

$(-)$ : negative; (+): positive; i-ELISA: indirect Enzyme-Linked Immunosorbent Assay; RBPT: Rose Bengal Plate test.

(10.8\% [8.6-12.3\%]) for RBPT and 91 (8.8\% [7.1-10.5\%]) for i-ELISA (Table 1). The seropositive reactors were 65 $(12,2 \%$ [9.4-15.0]) for RBPT and $60(11,3 \%[8,6 ; 14,0])$ for i-ELISA in the Adamawa Region and $43(8,2 \%[5,8 ; 10,6])$ for RBPT and $31(6,1 \%[4,0 ; 8,2])$ for i-ELISA in the North Region. The distribution of seropositive reactors according to locality is shown in Figure 2.

From a total of 82 herds included in the study, 38 $(46,2 \%[35,4 ; 57,0])$ herds for RBPT and $22(26,6 \%[17,0$; $36,2])$ herds for i-ELISA had at least one animal that tested positive. The herds were $20(46,4 \%[31,5 ; 61,3])$ for RBPT and $15(34,7 \%[20,5 ; 48,9])$ for $\mathrm{i}$-ELISA in the Adamawa Region and $18(46,0 \%[30,3 ; 61,6])$ for RBPT and $7(17,7 \%[5,7 ; 29,7])$ for i-ELISA in the North Region. 
TABLE 2: Risk factor model for brucellosis seropositivity in individual cattle in Adamawa and North Regions of Cameroon $(n=1031)$.

\begin{tabular}{|c|c|c|c|c|c|}
\hline Factor & Variable & $\begin{array}{l}\text { Number } \\
\text { (positive) }\end{array}$ & $\begin{array}{c}\text { Seropositivity using } \\
\text { i-ELISA [95\% CI] }\end{array}$ & $\begin{array}{l}\text { Odds ratio } \\
{[95 \% \mathrm{CI}]}\end{array}$ & $P$ value \\
\hline \multirow{2}{*}{ Region } & North & $509(31)$ & $6.1 \%[4.0-8.2]$ & 1 & - \\
\hline & Adamawa & $522(60)$ & $11.5 \%[8.8-14.2]$ & $2.0[1.2-3.1]$ & 0.003 \\
\hline \multirow{6}{*}{ Locality } & Vina & $117(2)$ & $1.7 \%[0-4.0]$ & 1 & - \\
\hline & Mbere & $187(12)$ & $6.4 \%[2.9-9.9]$ & $3.9[0.9-17.9]$ & 0.076 \\
\hline & Benoue & $134(21)$ & $15.7 \%$ [9.5-21.8] & $10.7[2.4-46.6]$ & 0.002 \\
\hline & Faro-et-Deo & $218(46)$ & $21.1 \%$ [15.7-26.5] & $15.4[3.7-64.6]$ & $<0.0001$ \\
\hline & Mayo-Louti & $117(10)$ & $8.5 \%$ [3.4-13.5] & $5.4[1.1-25.1]$ & 0.032 \\
\hline & Mayo Rey & $258(0)$ & $0 \%$ & & \\
\hline \multirow{3}{*}{ Herd size } & $\leq 30$ & $69(2)$ & $2.9 \%[1.0-6.8]$ & 1 & - \\
\hline & $30-59$ & $279(38)$ & $13.6 \%[9.6-17.6]$ & $0.5[0.3-0.8]$ & 0.003 \\
\hline & $\geq 60$ & $683(51)$ & $7.5 \%[5.5-9.5]$ & $0.2[0.0-0.8]$ & 0.024 \\
\hline \multirow{2}{*}{ Livestock systems } & Semi-intensive & $645(55)$ & $8.5 \%[6.3-10.6]$ & 1 & - \\
\hline & Extensive & $386(36)$ & $9.3 \%[6.4-12.2]$ & $1.1[0.7-1.7]$ & 0.662 \\
\hline \multirow{2}{*}{ Contact with wildlife } & Yes & $476(46)$ & $9.7 \%[7.0-12.3]$ & 1 & - \\
\hline & No & $555(45)$ & $8.1 \%[5.8-10.4]$ & $0.8[0.5-1.3]$ & 0.381 \\
\hline \multirow{2}{*}{ Knowledge of brucellosis } & Yes & $301(15)$ & $5.0 \%[2.5-7.5]$ & 1 & - \\
\hline & No & $339(40)$ & $11.8 \%$ [8.4-15.2] & $2.5[1.4-4.7]$ & 0.003 \\
\hline \multirow{2}{*}{$\begin{array}{l}\text { Occupational risk of } \\
\text { brucellosis }\end{array}$} & Yes & $164(10)$ & $6.1 \%[2.4-9.8]$ & 1 & - \\
\hline & No & $476(48)$ & $10.1 \%[7.4-12.8]$ & $1.7[0.8-3.5]$ & 0.129 \\
\hline \multirow{4}{*}{ Breed } & Mbororo (red) & $82(5)$ & $0.5 \%[0-2.0]$ & 1 & - \\
\hline & Fulani (white) & $167(20)$ & $1.9 \%[0-4.0]$ & $1.5[0.7-3.3]$ & 0.295 \\
\hline & Gudali & $715(58)$ & $5.6 \%[3.9-7.3]$ & $1.5[0.9-2.6]$ & 0.123 \\
\hline & Crossbreed ${ }^{*}$ & $67(8)$ & $0.8 \%[0-2.9]$ & $0.6[0.2-1.8]$ & 0.374 \\
\hline \multirow{2}{*}{ Sex } & Female & $852(83)$ & $9.7 \%[7.7-11.7]$ & 1 & - \\
\hline & Male & $179(8)$ & $4.5 \%[1.5-7.5]$ & $0.43[0.20-0.91]$ & 0.028 \\
\hline \multirow{3}{*}{ Age (years) } & Young $(\leq 4)$ & $116(8)$ & $6.9 \%[2.3-11.5]$ & 1 & - \\
\hline & Adult (5-8) & $818(65)$ & $7.9 \%[6.0-9.7]$ & $1.6[0.9-2.8]$ & 0.087 \\
\hline & Old $(\geq 9)$ & $97(18)$ & $18.6 \%[10.8-26.3]$ & $3.8[1.9-7.6]$ & $<0.0001$ \\
\hline \multirow{3}{*}{ Body Condition Score } & Poor $(<3)$ & $33(1)$ & $3.0 \%[0.0-8.8]$ & 1 & - \\
\hline & Good (3-4) & $887(82)$ & $9 \%[7.3-11.1]$ & $0.8[0.3-1.6]$ & 0.481 \\
\hline & Very Good (>4) & $111(8)$ & $7.2 \%[2.4-12.0]$ & $0.3[0-2.3]$ & 0.248 \\
\hline \multirow{2}{*}{ Abortion } & Yes & $310(20)$ & $6.5 \%[3.7-9.2]$ & 1 & - \\
\hline & No & $330(35)$ & $10.6 \%[7.3-13.9]$ & $1.7[1.0-3.0]$ & 0.063 \\
\hline \multirow{2}{*}{ Stillbirth } & Yes & $244(19)$ & $7.8 \%[4.4-11.2]$ & 1 & - \\
\hline & No & $394(36)$ & $9.1 \%$ [6.3-11.9] & $1.2[0.7-2.1]$ & 0.555 \\
\hline \multirow{2}{*}{ Retained placenta } & Yes & $162(12)$ & $8.0 \%[3.8-12.2]$ & 1 & - \\
\hline & No & $478(42)$ & $8.8 \%$ [6.3-11.3] & $1.1[0.6-2.1]$ & 0.765 \\
\hline
\end{tabular}

\#Observed reactions of individual animals $(n=1031)$ or of animals of farmers who responded to questionnaire ( $n$ depends on number of animals of the farmer) were used in the category. ${ }^{*}$ Crossbreed between local breeds.

A true prevalence of $5.4 \%(0.4-10.5)$ and test characteristics of $58.3 \%(26.4-92.7)$ and $89.6 \%(80.4-99.4)$ as sensitivity and $92.1 \%(88.7-95.2)$ and $95.7 \%(91.1-99.7)$ as specificity for RBPT and i-ELISA, respectively, were estimated after combining the results with expert's opinion on the Bayesian model using WinBUGS after 30,000 iterations.

3.2. Factors Affecting Seroprevalence of Bovine Brucellosis. The logistic regression revealed that region, locality, herd size, and knowledge of brucellosis as well as sex and age had effect $(P<0.05)$ on individual level seropositivity of brucellosis (Table 2). However, there was no difference $(P>$ $0.05)$ between seroprevalence for cattle $\leq 4$ years old $(6.9 \%$ (2.3-11.5)) compared to cattle $>4$ years old $(9.1 \%(7.4-10.8))$ $(\mathrm{OR}=1.3(0.6-2.8) ; P=0.438)$. The seroprevalence at the individual cattle level was significantly higher in the Adamawa (11.5\%) than in the North (6.1\%) Region while Faro-et-Deo (21.1\%), Benoue (15.7\%), and Mayo-Louti (8.5\%) localities and animals owned by farmers who were ignorant of brucellosis showed increased $(P<0.05)$ odds of having 
seropositive reactors than other localities and farmers who had knowledge of brucellosis, respectively. Also, animal seroprevalence significantly increased with the increase in herd size (Table 2). Breed, body condition, management system, contact with wildlife, abortion, stillbirth, and retained fetal membranes had no effects $(P>0.05)$ on the seroprevalence.

\section{Discussion}

The study revealed that bovine brucellosis is endemic in the Adamawa and North Regions of Cameroon and the overall individual level seroprevalence $(10.5 \%$ for RBPT and $8.8 \%$ for i-ELISA) is different from those previously reported elsewhere in the country. Using competitive ELISA, Bayemi et al. [9] reported higher seroprevalence (8.4\%) in Holstein cattle in the Northwest Region while Scolamacchia et al. [18] reported lower rates (3\%) in indigenous cattle in Adamawa Region. Lower seroprevalence was also reported by Ojong [17] (4.6\%) using RBPT in indigenous cattle in Northwest region. The finding of this study is close to the report of SheyNjila et al. [11] (9.64\%) who used indirect ELISA in indigenous cattle in the Western Highlands Regions. However, Bornarel and Akakpo [37] found a brucellosis seroprevalence of $12.5 \%$ in the Northern Cameroon and several other studies have reported brucellosis seroprevalence ranging from 7 to $31 \%$ [37, 38, 39, 40, 41, 42]. Lower seroprevalence rates of brucellosis have been reported in indigenous cattle in Niger (1.3\%) [38], Ivory Coast (4.6\%) [34], Nigeria (3.9\%) [3], Chad (2.6\%) [1, 39], Central Africa Republic (3.3\%) [40], Uganda (3.3\%) [41], Zimbabwe (5.6\%) [42, 43], and Ethiopia (2.4-3.9) $[4,7,44]$. Higher rates have been reported in Ivory Coast (8.8-10.3\%) [35, 45], Zambia (18.7\%) [46], Mali (22\%) [47], Burkina Faso (13.2\%) [48], and Algeria (9.7\%) [49]. The herd level seroprevalence (46.3\% (35.5-57.1) for RBPT and $30.5 \%(20.6-40.4)$ for i-ELISA) in the present study is higher than that reported by Scolamacchia et al. [18] (16\%) in traditional extensive systems in Adamawa region. Similar herd prevalence was reported in Zimbabwe (25\%) [42], while lower rates were reported in Ethiopia (9.2-15\%) [7] and Niger (13.7\%) [38] and higher rates in Ethiopia (42.31-45.9\%) [4, 44, 50], Zimbabwe (40.0\%) [42], and Algeria (31.5\%) [49]. Relative sensitivity of $33 \%$ and specificity of $96 \%$ of delayed hypersensitivity test to brucellin (DHTB) in comparison to serological assays to detect brucellosis in zebu cattle were recorded in Northern Cameroon [51]. However, considering the limitations of DHTB and serological methods, the most sensitive brucellosis diagnostic procedure is a combination of both tests, where subjects are scored as positive if they are positive to either or both tests [51].

The relatively high levels of individual and herd seroprevalence recorded in this study are indications of high level introduction of infected animals to herds, transhumance, and high level mixing of herds such as grazing in communal pasture, livestock markets and, veterinary interventions. Variation in management practices (level of intensification and hygiene practices) $[7,14,15,43]$ in farms has been associated with differences in seroprevalence rates reports in various studies. However, the differences in prevalence rates reported in Cameroon and other parts of Africa could also be associated with the protocol adopted such as the type and number of diagnostic tests used. The protocol could have involved one test or more than one test in series (screening test followed by confirmation of positive reactors by another test) or in parallel (all tests are applied on the sampled animals independently). The evolution of the disease could be responsible for the different seroprevalence rates reported. Furthermore, close antigenic cross-reactivity with other bacterial infections (Yersinia, Xanthomonas, Salmonella, Streptococci, E. coli, tuberculosis) can lead to false positive results being encountered in serological diagnosis of brucellosis $[35,52$, 53].

The Brucella ELISA test is generally considered to have higher sensitivity and specificity in determining Brucella specific antibodies than other serological tests $[52,54]$. However, Cakan et al. [55] found that ELISA test for brucellosis was more sensitive only when both IgG and IgM were used, though their titre alone did not represent disease status. The sensitivity and specificity of ELISA IgG (45.6\% and $97.1 \%$, resp.) were reported to be lower than those of the standard tube agglutination test (95.6\% and 100\%, resp.) [55]. Therefore, results of both standard tube agglutination test and RBPT, which have similar sensitivity and specificity, should be interpreted according to the level of endemicity and seroprevalence rate of the population [53]. Estimation of sensitivity and specificity of a test requires knowledge of the true disease status and using a gold standard test. However, in the absence of such a gold test a Bayesian approach is used to evaluate the characteristics of the tests $[20,22,23,56]$. Bayesian method provides a stable point and interval estimate without the necessity of large sample size [23]. The sensitivity of RBPT in the present study (58.3\% (26.4-92.7\%)) is similar to the finding of Sanogo et al. [34] (54.9\% (23.5-95.1)) and lower than the finding of Getachew et al. [57] $(89.6 \%$ (79.9-95.8)). The specificity of RBPT (92.1\% (88.7-95.2) was fairly high and similar to the finding of Getachew et al. [57] (84.5\% (68-94.8)) and Sanogo et al. [34] (97.7\% (95.3-99.4)). The indirect ELISA in this study showed the best sensitivity (86.6\% (80.4-99.4)) and specificity (95.7\% (91.1-99.7)) for bovine brucellosis compared to RBPT and was similar to the finding of Sanogo et al. [34] who reported sensitivity $(96.1 \%$ (92.7-99.8)) and specificity (95\% (91.1-99.6)) and Gatechew et al. [57] who reported sensitivity (96.8\% (92.3-99.1)) and specificity (96.3\% (91.7-98.8)). This study estimated the true seroprevalence of brucellosis to be $5.4 \%(4-10.5)$ at individual animal level and $25.6 \%(16.2-35)$ at herd level. However, there are sporadic reports of outbreaks of bovine brucellosis in Cameroon to the World Organization For Animal Health, which is not indicative of the absence of the disease but rather of an underestimation [58], and other findings had concluded that the prevalence of the disease exceeds $5 \%$ in the country [59].

The higher seroprevalence recorded in the Adamawa Region (11.3\%) compared to the North Region (6.1\%) was associated with differences in climatic conditions between the regions. According to logistic regression analysis model, cattle in the Adamawa Region and areas where transhumance is practiced have increased odds of being seropositive than cattle in the North Region and areas which do not practice 
transhumance, respectively. The Adamawa Region has the typical tropical humid (Savannah Guinean) climate which is more favourable to the occurrence of brucellosis compared to the tropical dry (Sudano-Sahelian) climate of the North Region. This finding agrees with those of Sanogo et al. [34] who reported higher seroprevalence rates in Guinean zones than Sudano or Sudano-Sahelian zones in West Africa. Therefore, localities that practiced high transhumance and reduced levels of intensification revealed higher seroprevalence compared to more sedentary and intensified husbandry practices. Ibrahim et al. [7] and Boukary et al. [38] have reported that transhumance animals were major risk factor for brucellosis in sedentary animals and that the prevalence of brucellosis increased in sedentary herds that share same environments (pasture, water points, shelter) with animals on transhumance. In conformity with the seroprevalence rates reported in various parts of Africa $[1,3,34,35,38,40,45$, 46], previous works have observed higher rates in the more humid (4.6-9.6\%) [9, 11, 17] than dryer (3\%) [18] regions of Cameroon. However, the reason for higher individual seroprevalence rates recorded in regions with dry climates such as Mali [47], Burkina Faso [48], and Algeria [49] is not clear.

The study showed that female and old ( $\geq 9$ years) cattle have increased odds of being seropositive reactors than bulls and younger cattle, respectively. This agrees with previous studies $[3,4,15,39,45,48]$ which explain that the economic and reproductive life of female cattle are much longer than those of male cattle and that the older the animal is, the longer the potential exposure to the disease is. Management practices in farms may play additional roles in the different seropositivity due to sex and age. However, Bayemi et al. [9] reported that young animals ( $\leq 3$ years old) accounted for nearly half of the seropositive animals in small scale farms, while Akinseye et al. [3] and Ojong [17] did not observe differences in seropositivity due to sex.

Herd size was an important factor with significant effect on herd level and individual level seroprevalence, and the seroprevalence increased with herd size. This finding agrees with the reports of Berhe et al. [44], Boukary et al. [38], Makita et al. [8], and Sanogo et al. [34]. Though Asgedom et al. [4] did not observe difference in seropositivity with respect to herd size, an increase in herd size usually associated with poor hygiene of the farm [7] and stocking density has been reported as important determinant of brucellosis infection [60]. Furthermore, [43] have identified area, keeping mixed breed herds, stocking density, and herd size as independently associated with increased counts of seropositive cattle in a herd.

In addition to region, locality, and herd size, cattle owned by farmers who were ignorant of brucellosis showed more seropositivity than animals owned by farmers who had knowledge of brucellosis. Also, cattle owned by farmers who were ignorant of the occupational risk of brucellosis showed nonsignificant higher seropositivity than animals of farmers who had knowledge of the occupational risk of brucellosis. This could be explained by the fact that endemic zoonoses including bovine brucellosis remain widely neglected in low income countries [13] such as Cameroon, and there is lack of health and zoonoses education of farmers. Good hygiene practices [4] and protective effects towards animal and human brucellosis [61] in farms of owners with good knowledge of brucellosis have been reported. Poor hygiene practices and uncontrolled animals movements which posed high risks of transmitting brucellosis within and in between the herds were reported in farms where the owners were ignorant of brucellosis [4].

Breed, body condition, management system, contact with wildlife, abortion, stillbirth, and retained fetal membranes had no significant effects on the seroprevalence. The finding agrees with Asgedom et al. [4] regarding breed and with Ibrahim et al. [7] regarding management system but disagrees with Bayemi et al. [10] and Shirima et al. [62] who reported that animals on extensive management were more likely to be exposed to brucellosis compared to animals that are sedentary. This finding agrees with Kebede et al. [50] regarding abortion and retained fetal membranes and differs with Muma et al. [63], Ibrahim et al. [7], and Boukary et al. [38] with regard to the occurrence of abortion. However, the nonsignificant difference due to breed, management system, abortion, stillbirth, and retained fetal membranes recorded in this study was associated with high levels of uncontrolled movements and mixing of animals (transhumance and nontranshumance animals) irrespective of breed. Asgedom et al. [4] has revealed the existence of a strong association between number of services per conception and seropositivity of brucellosis. The number of services per conception increases when the cattle were repeatedly experiencing abortion, retained fetal membrane, and other reproductive health problems. Brucellosis affects the reproductive tract causing abortion and retained fetal membrane that usually leads to uterine infection and hence poor conception rate $[1,4]$. The study agrees with Kungu et al. [64] for body condition in contrast to Bayemi et al. [10] who reported higher seroprevalence in animals with good body condition. Contrary to this study, brucellosis has been reported to be endemic in domestic animals in the livestock-wildlife interface areas [63], and contact with wildlife significantly increases seropositivity to the disease in domestic animals $[15,17]$. Antibodies to Brucella spp. have been found in wildlife (e.g., buffalo) in Africa and cattle may become infected when in contact or sharing the same grazing area with infected animals of different species [15].

Brucellosis is endemic at different prevalence levels in parts of Cameroon. This study recorded overall moderate seroprevalence at individual animal level and high seroprevalence at herd level. Management related factors such as region, locality, herd size, and knowledge of brucellosis and animal related factors such as sex and age were associated with seropositivity of brucellosis. Brucellosis is a major public and animal health problem where bovine brucellosis is endemic. However, no specific control program exists at national level for zoonotic brucellosis in Cameroon. The need for an integrated disease control approach mimicking the one health approach and involving interdisciplinary strategies between animal and human health experts as well as concerned target stakeholders and affected communities cannot be overemphasized. This study provides important 
information on the epidemiology of bovine brucellosis in the Adamawa and North Regions of Cameroon and highlights the need for control measures and enhancing of public awareness of the zoonotic occurrence and transmission of bovine brucellosis in the country.

\section{Conflicts of Interest}

The authors declare that there are no conflicts of interest regarding the publication of this paper.

\section{Acknowledgments}

The authors are grateful to the staff of MINEPIA, PAPA/ ADFL Program and Veterinary Research Laboratory IRAD Wakwa for allowing the collection and analysis of samples and to cattle professionals of the North and Adamawa Regions of Cameroon for their generous cooperation. With the support of Dr. S. Fon-Tebug, the Rose Bengal reagents used in this study were donated by Professor Ignacio Moriyon, Department of Microbiology and Parasitology, Medical Schools, and Institute for Tropical Health, University of Navarra, Pamplona, Spain.

\section{Supplementary Materials}

Bayesian model for the estimation of the value of characteristics of the tests. (Supplementary Materials)

\section{References}

[1] E. Schelling, C. Diguimbaye, S. Daoud et al., "Brucellosis and Q-fever seroprevalences of nomadic pastoralists and their livestock in Chad," Preventive Veterinary Medicine, vol. 61, no. 4, pp. 279-293, 2003.

[2] OIE, Manual of Diagnostic Tests and Vaccines for Terrestrial Animals 2009, World Organisation for Animal Health, Paris, France, 2009.

[3] V. O. Akinseye, H. K. Adesokan, A. J. Ogugua et al., "Seroepidemiological survey and risk factors associated with bovine brucellosis among slaughtered cattle in Nigeria," Onderstepoort Journal of Veterinary Research, vol. 83, no. 1, Article ID a1002, 2016.

[4] H. Asgedom, D. Damena, and R. Duguma, "Seroprevalence of bovine brucellosis and associated risk factors in and around Alage district, Ethiopia," SpringerPlus, vol. 5, no. 1, article no. 851, 2016.

[5] M. J. Ducrotoy, W. J. Bertu, R. A. Ocholi et al., "Brucellosis as an Emerging Threat in Developing Economies: Lessons from Nigeria," PLOS Neglected Tropical Diseases, vol. 8, no. 7, Article ID e3008, 2014.

[6] T. Marcotty, F. Matthys, J. Godfroid et al., "Zoonotic tuberculosis and brucellosis in Africa: neglected zoonoses or minor public-health issues? The outcomes of a multi-disciplinary workshop," Annals of Tropical Medicine and Parasitology, vol. 103, no. 5, pp. 401-411, 2009.

[7] N. Ibrahim, K. Belihu, F. Lobago, and M. Bekana, "Seroprevalence of bovine brucellosis and its risk factors in Jimma zone of Oromia Region, South-western Ethiopia," Tropical Animal Health and Production, vol. 42, no. 1, pp. 35-40, 2009.
[8] K. Makita, E. M. Fèvre, C. Waiswa, M. C. Eisler, M. Thrusfield, and S. C. Welburn, "Herd prevalence of bovine brucellosis and analysis of risk factors in cattle in urban and peri-urban areas of the Kampala economic zone, Uganda," BMC Veterinary Research, vol. 7, article no. 60, 2011.

[9] P. H. Bayemi, E. C. Webb, M. V. Nsongka, H. Unger, and H. Njakoi, "Prevalence of Brucella abortus antibodies in serum of Holstein cattle in Cameroon," Tropical Animal Health and Production, vol. 41, no. 2, pp. 141-144, 2009.

[10] P. H. Bayemi, G. D. Mah, K. Ndamukong et al., "Bovine Brucellosis in Cattle Production Systems in the Western Highlands of Cameroon," International Journal of Animal Biology, vol. 1, pp. 38-44, 2015.

[11] O. Shey-Njila, M. Daouda, E. Nya et al., "Enquête sérologique de la brucellose bovine au Cameroun," Revue d'élevage et de médecine vétérinaire des pays tropicaux, vol. 58, no. 3, p. 139, 2005.

[12] J. Awah-Ndukum, AC. Kudi, GS. Bah, G. Bradley, V. NguNgwa, and PL. Dickmu, "Risk factors analysis and implications for public health of bovine tuberculosis in the highlands of Cameroon," in Bulletin of Animal Health and Production in Africa, vol. 62, pp. 353-376, 2014.

[13] J. E. B. Halliday, K. J. Allan, D. Ekwem, S. Cleaveland, R. R. Kazwala, and J. A. Crump, "One health: Endemic zoonoses in the tropics: A public health problem hiding in plain sight," Veterinary Record, vol. 176, no. 9, pp. 220-225, 2015.

[14] J. B. Muma, K. L. Samui, J. Oloya, M. Munyeme, and E. Skjerve, "Risk factors for brucellosis in indigenous cattle reared in livestock-wildlife interface areas of Zambia," Preventive Veterinary Medicine, vol. 80, no. 4, pp. 306-317, 2007.

[15] S. Mazeri, F. Scolamacchia, I. G. Handel, K. L. Morgan, V. N. Tanya, and B. M. D. C. Bronsvoort, "Risk factor analysis for antibodies to Brucella, Leptospira and C. burnetii among cattle in the Adamawa Region of Cameroon: A cross-sectional study," Tropical Animal Health and Production, vol. 45, no. 1, pp. 617623, 2012.

[16] K. Nielsen and WL. Yu, "Serological diagnosis of brucellosis," Contributions, Sec. Biol. Med. Sci., MASA, XXXI, vol. 1, pp. 6589, 2010.

[17] B. W. Ojong, "Situation of brucellosis in beef-type cattle raised under different husbandry systems in Cameroon. Establishment of a multi-sectorial strategy for the control of brucellosis in the main peri-urban dairy production zones of West and Central Africa Project Outline," DAKAR 15, vol. 18, p. 2011, 2015.

[18] F. Scolamacchia, I. G. Handel, E. M. Fèvre, K. L. Morgan, V. N. Tanya, and B. M. D. C. Bronsvoort, "Serological patterns of brucellosis, leptospirosis and Q fever in Bos indicus cattle in Cameroon," PLoS ONE, vol. 5, no. 1, Article ID e8623, 2010.

[19] F. P. Poester, K. Nielsen, L. E. Samartino, and W. L. Yu, "Diagnosis of Brucellosis," The Open Veterinary Science Journal, vol. 4, pp. 46-60, 2010.

[20] R. Pouillot, G. Gerbier, and I. A. Gardner, ““TAGS”, a program for the evaluation of test accuracy in the absence of a gold standard," Preventive Veterinary Medicine, vol. 53, no. 1-2, pp. 67-81, 2002.

[21] R. Poulloit and R. Gerbier, "A Bayesian method for the evaluation of the sensitivity and specificity of correlated diagnostic tests in the absence of gold standard," in Proceedings of the 9th International Symposium on Veterinary Epidemiology and Economics, 2000, http://www.sciquest.org.nz/. 
[22] C. Enøe, S. Andersen, V. Sørensen, and P. Willeberg, "Estimation of sensitivity, specificity and predictive values of two serologic tests for the detection of antibodies against Actinobacillus pleuropneumoniae serotype 2 in the absence of a reference test (gold standard)," Preventive Veterinary Medicine, vol. 51, no. 3-4, pp. 227-243, 2001.

[23] C. Enøe, M. P. Georgiadis, and W. O. Johnson, "Estimation of sensitivity and specificity of diagnostic tests and disease prevalence when the true disease state is unknown," Preventive Veterinary Medicine, vol. 45, no. 1-2, pp. 61-81, 2000.

[24] MINEPIA, Rapport d'activités 2012. Division des Etudes, de la Coopération et des Statistiques, 2012.

[25] M. Thrusfield, Veterinary epidemiology, vol. 610, Blackwell Science Ltd, a Blackwell, Oxford, UK, 2007.

[26] R. Blench, Traditional Livestock Breeds: Geographical Distribution And Dynamics in Relation to The Ecology of West Africa, vol. 67, Overseas Development Institute, London, UK, 1999.

[27] MINEPIA, "La stratégie sectoriel de l'élevage, des peches et industries animales. In: Cabinet Management 2000 MINEPIA," in Cabinet Management, Ministry of Livestock, Fisheries and Animal Industries, Yaounde, Yaounde, Cameroon, 2000.

[28] J. Turton, How to estimate the age of cattle Onderspoort, National Department of Agriculture, ARC- Onderspoort Veterinary Institute, South Africa, 1999.

[29] G. G. Alton, L. M. Jones, R. D. Angus, and J. M. Verger, "Techniques for the brucellosis laboratory, INRA," Techniques for the brucellosis laboratory, INRA, 1988.

[30] J. N. Limet, P. Kerkhofs, R. Wijffels, and P. Dekeyser, "Le diagnostic sérologique de la brucellose bovine par ELISA," Annales De Medecine Veterinaire, vol. 132, pp. 565-575, 1988.

[31] C. Saegerman, L. De Waele, D. Gilson et al., "Evaluation of three serum i-ELISAs using monoclonal antibodies and protein $\mathrm{G}$ as peroxidase conjugate for the diagnosis of bovine brucellosis," Veterinary Microbiology, vol. 100, no. 1-2, pp. 91-105, 2004.

[32] D. Berkvens, N. Speybroeck, N. Praet, A. Adel, and E. Lesaffre, "Estimating disease prevalence in a Bayesian framework using probabilistic constraints," Epidemiology, vol. 17, no. 2, pp. 145153, 2006.

[33] N. Praet, P. Dorny, C. Saegerman, T. Marcotty, and D. Berkvens, "Estimation de la prévalence d'une maladie et des caractéristiques des tests diagnostiques par une approche bayésienne," Épidémiologie et Santé Animale, vol. 49, pp. 113$130,2006$.

[34] M. Sanogo, E. Thys, Y. L. Achi et al., "Bayesian estimation of the true prevalence, sensitivity and specificity of the Rose Bengal and indirect ELISA tests in the diagnosis of bovine brucellosis," The Veterinary Journal, vol. 195, no. 1, pp. 114-120, 2013.

[35] M. Sanogo, B. Cissé, M. Ouattara et al., "Prévalence réelle de la brucellose bovine dans le centre de la Côte d'Ivoire," Revue d'élevage et de médecine vétérinaire des pays tropicaux, vol. 61, no. 3-4, p. 147, 2008.

[36] W. J. Rogan and B. Gladen, "Estimating prevalence from the results of a screening test," American Journal of Epidemiology, vol. 107, no. 1, pp. 71-76, 1978.

[37] P. Bornarel and A. J. Akakpo, "Epidemiology of bovine brucellosis in tropical Africa. 3. Serological survey in Cameroon," in Revue de Médecine Vétérinaire, vol. 138, pp. 55-58, 1987.

[38] A. R. Boukary, C. Saegerman, E. Abatih et al., "Seroprevalence and potential risk factors for Brucella spp. infection in traditional cattle, sheep and goats reared in urban, periurban and rural areas of Niger," PLoS ONE, vol. 8, no. 12, Article ID e83175, 2013.
[39] A. Delafosse, F. Goutard, and E. Thebaud, "Epidémiologie de la tuberculose et de la brucellose des bovins en zone périurbaine d'Abéché (Tchad)," Revue d'élevage et de médecine vétérinaire des pays tropicaux, vol. 55, no. 1, p. 5, 2002.

[40] E. Nakouné, O. Debaere, F. Koumanda-Kotogne, B. Selekon, F. Samory, and A. Talarmin, "Serological surveillance of brucellosis and Q fever in cattle in the Central African Republic," Acta Tropica, vol. 92, no. 2, pp. 147-151, 2004.

[41] J. W. Magona, J. Walubengo, T. Galiwango, and A. Etoori, "Seroprevalence and potential risk of bovine brucellosis in zerograzing and pastoral dairy systems in Uganda," Tropical Animal Health and Production, vol. 41, no. 8, pp. 1765-1771, 2009.

[42] G. Matope, E. Bhebhe, J. B. Muma et al., "Seroprevalence of brucellosis and its associated risk factors in cattle from smallholder dairy farms in Zimbabwe," Tropical Animal Health and Production, vol. 43, no. 5, pp. 975-982, 2011.

[43] G. Matope, E. Bhebhe, J. B. Muma, A. Lund, and E. Skjerve, "Herd-level factors for Brucella seropositivity in cattle reared in smallholder dairy farms of Zimbabwe," Preventive Veterinary Medicine, vol. 94, no. 3-4, pp. 213-221, 2010.

[44] G. Berhe, K. Belihu, and Y. Asfaw, "Seroepidemiological investigation of bovine brucellosis in the extensive cattle production system of Tigray region of Ethiopia," International Journal of Applied Research in Veterinary Medicine, vol. 5, pp. 65-71, 2007.

[45] M. Sanogo, E. Abatih, E. Thys, D. Fretin, D. Berkvens, and C. Saegerman, "Risk factors associated with brucellosis seropositivity among cattle in the central savannah-forest area of Ivory Coast," Preventive Veterinary Medicine, vol. 107, no. 1-2, pp. 5156, 2012.

[46] H. M. Chimana, J. B. Muma, K. L. Samui et al., "A comparative study of the seroprevalence of brucellosis in commercial and small-scale mixed dairy-beef cattle enterprises of Lusaka province and Chibombo district, Zambia," Tropical Animal Health and Production, vol. 42, no. 7, pp. 1541-1545, 2010.

[47] K. Tounkara, S. Maiga, A. Traoré, B. M. Seck, and A. J. Akakpo, "Epidemiology of bovine brucellosis in Mali: serologic investigation and initial isolation of strains of Brucella abortus," Revue Scientifique et Technique de l'OIE, vol. 13, no. 3, pp. 777786, 1994.

[48] A. Traore, H. T. Hamidou, B. Bale, W. R. David, Y. Nongasida, and S. Moumouni, "Prévalence globale des pathologies majeures liées à la production laitière bovine en système délevage intraurbain à Hamdallaye (Ouagadougou)," Biotechnol Agron Soc Environ, vol. 8, pp. 3-8, 2004.

[49] H. Aggad and L. Boukraa, "Prevalence of bovine and human brucellosis in western Algeria: Comparison of screening tests," Eastern Mediterranean Health Journal, vol. 12, no. 1-2, pp. 119128, 2006.

[50] T. Kebede, G. Ejeta, and G. Ameni, "Seroprevalence of bovine brucellosis in smallholder farms in central Ethiopia (WuchaleJida district)," Revue de Médecine Vétérinaire, vol. 159, no. 1, pp. 3-9, 2008.

[51] A. Martrenchar, B. M. Njanpop, A. Yaya, A. Njoya, and J. J. Tulasne, "Problems associated with tuberculosis and brucellosis skin-test methods in northern Cameroon," Preventive Veterinary Medicine, vol. 15, no. 2-3, pp. 221-229, 1993.

[52] M. Varshochi, J. Majidi, M. Amini, K. Ghabili, and M. M. Shoja, "False positive seroreactivity to brucellosis in tuberculosis patients: A prevalence study," Journal of General Internal Medicine, vol. 4, pp. 207-210, 2011. 
[53] F. Yildiz, E. Tanyel, CA. Hatipoglu, GT. Ertem, and N. Tulek, "Oral .B Evaluation of brucella tube agglination test in patients with brucellosis, patients with bacterial infection other than brucellosis and healthy subjects," Mikrobiyoloji Bulteni, vol. 39, pp. 211-217, 2005.

[54] A. Mert, R. Ozaras, F. Tabak et al., "The sensitivity and specificity of Brucella agglutination tests," DIAGNOSTIC MICROBIOLOGY AND INFECTIOUS DISEASE, vol. 46, no. 4, pp. 241243, 2003.

[55] G. Cakan, F. B. Bezirci, A. Kacka et al., "Assessment of diagnostic enzyme-linked immunosorbent assay kit and serological markers in human brucellosis," Japanese Journal of Infectious Diseases, vol. 61, no. 5, pp. 366-370, 2008.

[56] N. Toft, E. Jørgensen, and S. Højsgaard, “Diagnosing diagnostic tests: evaluating the assumptions underlying the estimation of sensitivity and specificity in the absence of a gold standard," Preventive Veterinary Medicine, vol. 68, no. 1, pp. 19-33, 2005.

[57] T. Getachew, G. Getachew, G. Sintayehu, M. Getenet, and A. Fasil, "Bayesian Estimation of Sensitivity and Specificity of Rose Bengal, Complement Fixation, and Indirect ELISA Tests for the Diagnosis of Bovine Brucellosis in Ethiopia," Veterinary Medicine international, vol. 2016, Article ID 8032753, 2016.

[58] O. Shey-Njila, J. Awah-Ndukum, PH. Bayemi, E. Nyah, PA. Zoli, and S. Geerts, Brucellosis in cameroon: current status and challenges for the future. All Africa Conference on Animal Agriculture: The role of biotechnology in animal agriculture to address poverty in Africa: Opportunities and challenges, Arusha, Tanzania, 2005.

[59] P. C. Lefèvre, Atlas des maladies infectieuses des ruminants. IEMVT-CIRAD, Maisons Alfort, 1991.

[60] M. K. Omer, E. Skjerve, G. Holstad, Z. Woldehiwet, and A. P. Macmillan, "Prevalence of antibodies to Brucella spp. in cattle, sheep, goats, horses and camels in the State of Eritrea; Influence of husbandry systems," Epidemiology and Infection, vol. 125, no. 2, pp. 447-453, 2000.

[61] T. B. Kozukeev, S. Ajeilat, E. Maes, and M. Favorov, "Risk factors for brucellosis-Leylek and Kadamjay districts, Batken Oblast, Kyrgyzstan, January-November, 2003.," Morbidity and Mortality Weekly Report (MMWR), vol. 55, pp. 31-34, 2006.

[62] G. M. Shirima, S. Cleaveland, and R. R. Kazwala, "Seroprevalence of brucellosis in smallholder, agro-pastoral, beef ranch and wild life animals in Tanzania," Bulletin of Animal Health and Production in Africa, vol. 55, pp. 13-21, 2007.

[63] J. B. Muma, K. L. Samui, V. M. Siamudaala et al., "Prevalence of antibodies to Brucella spp. and individual risk factors of infection in traditional cattle, goats and sheep reared in livestockwildlife interface areas of Zambia," Tropical Animal Health and Production, vol. 38, no. 3, pp. 195-206, 2006.

[64] J. M. Kungu, J. Okwee-Acai, C. Ayebazibwe, S. G. Okech, and J. Erume, "Seroprevalence and risk factors for brucellosis in cattle in Gulu and Amuru districts, Northern Uganda," African Journal of Biomedical Research, vol. 5, pp. 36-42, 2010. 

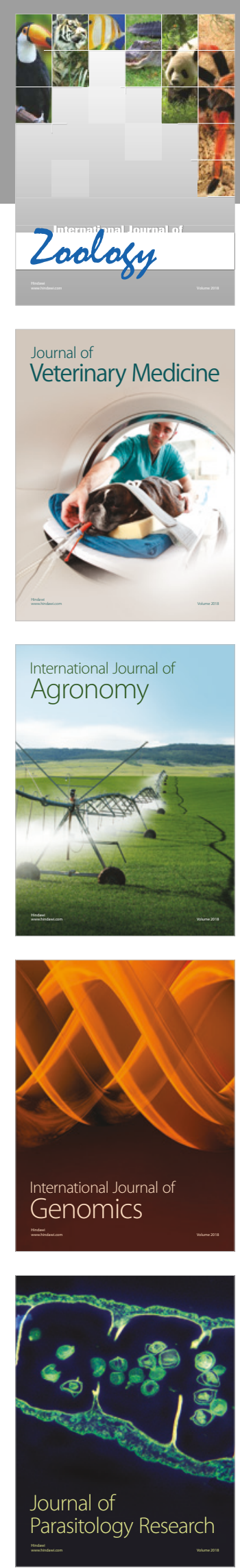

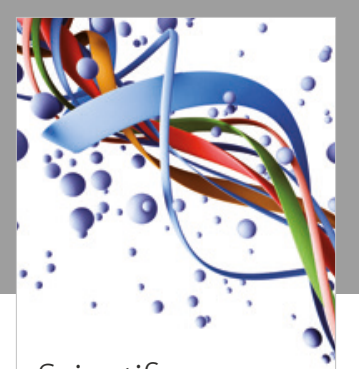

Case Reports in Veterinary Medicine Scientifica
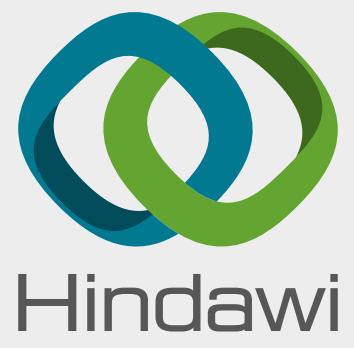

Submit your manuscripts at

www.hindawi.com
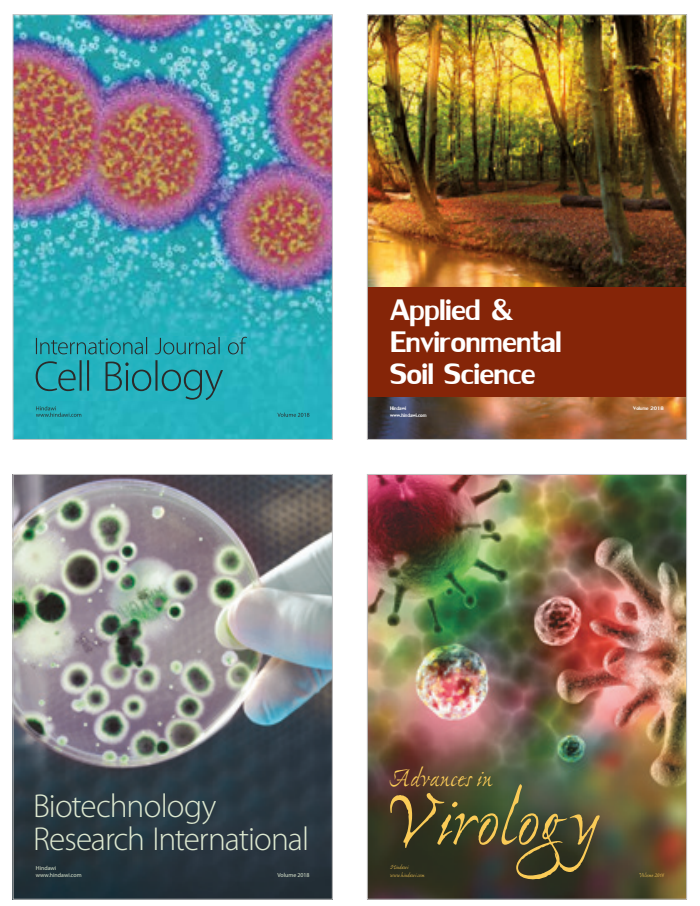

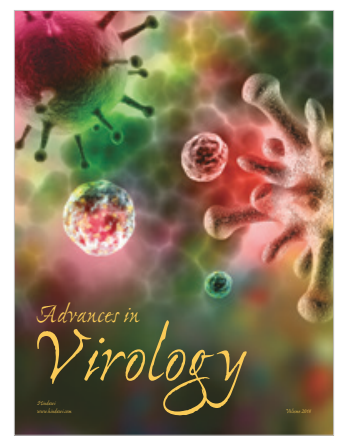

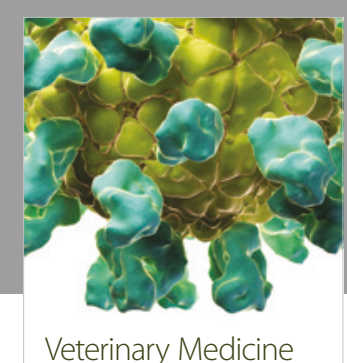
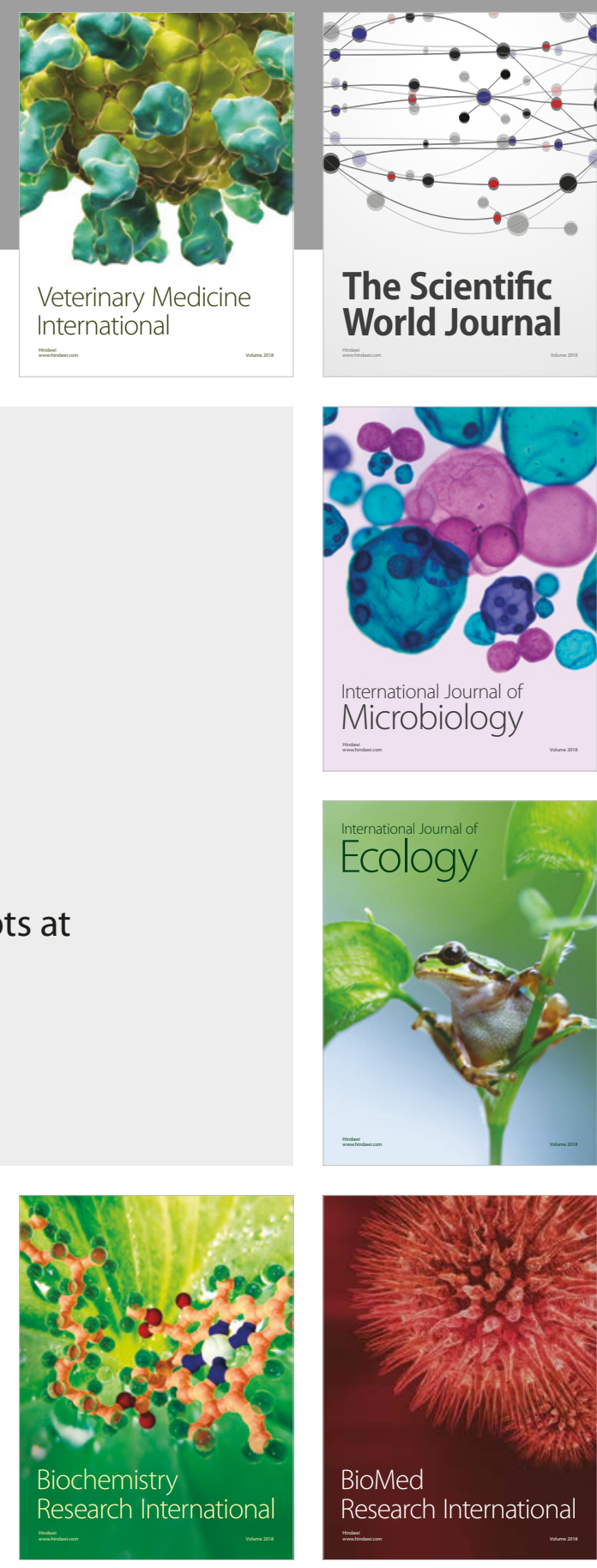

The Scientific World Journal

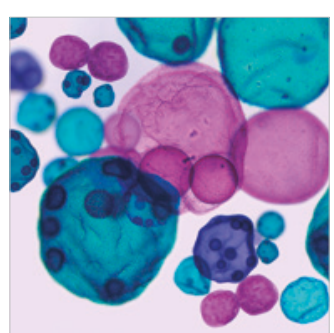

International Journal of Microbiology
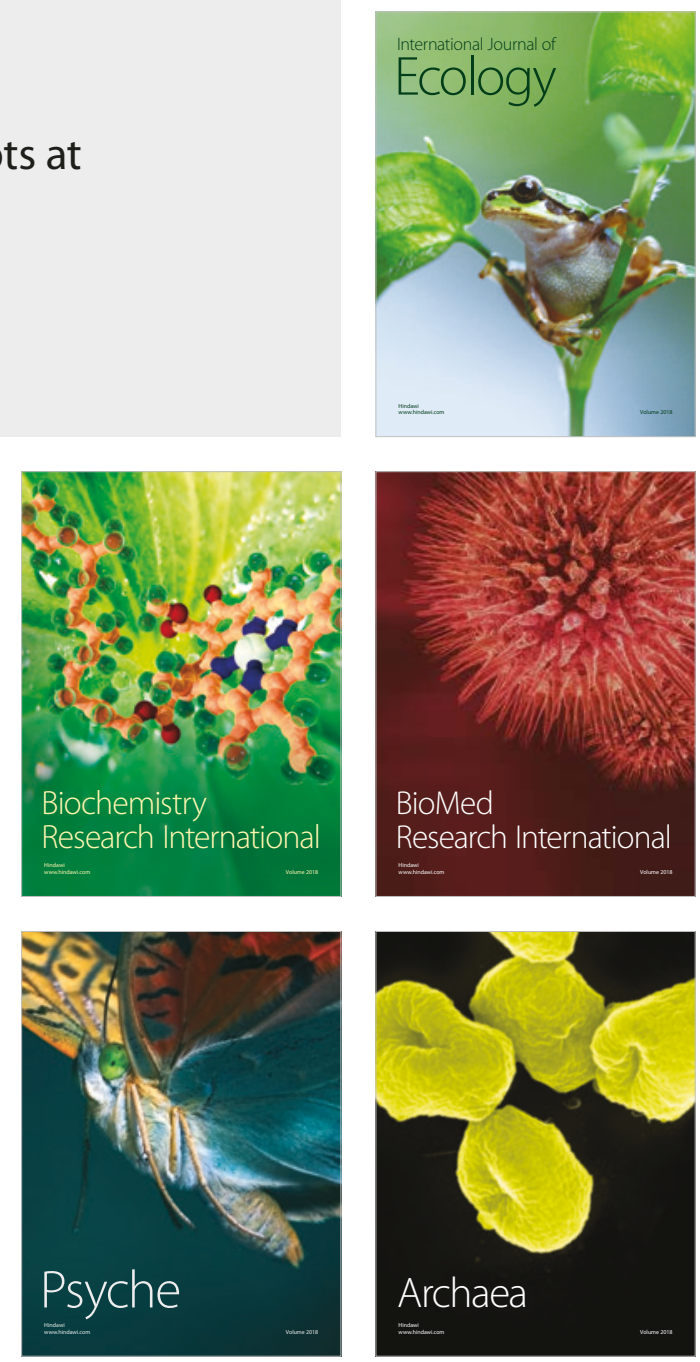